\title{
Relation Between the Behaviors of P-Wave and QT Dispersions in Elderly Patients with Heart Failure
}

\author{
Cláudia Szlejf, Jairo Rays, Otávio Celso Eluf Gebara, Núbia Welerson Vieira, Humberto Pierri, \\ Amit Nussbacher, João Batista Serro-Azul, Nelson Samesima, Carlos Alberto Pastore, \\ Maurício Wajngarten \\ São Paulo, SP - Brazil
}

Objective - To assess the relation between $P$-wave and QT dispersions in elderly patients with heart failure.

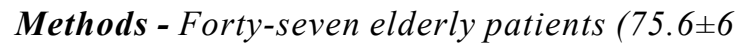
years) with stable heart failure in NYHA functional classes II or III and with ejection fractions of $37 \pm 6 \%$ underwent body surface mapping to analyze P-wave and QT dispersions. The degree of correlation between $P$-wave and $Q T$ dispersions was assessed, and P-wave dispersion values in patients with $Q T$ dispersion greater than and smaller than $100 \mathrm{~ms}$ were compared.

Results - The mean values of $P$-wave and $Q T$ dispersions were $54 \pm 14 \mathrm{~ms}$ and $68 \pm 27 \mathrm{~ms}$, respectively. The correlation between the 2 variables was $R=0.41$ ( $p=0.04)$. In patients with $Q T$ dispersion values $>100 \mathrm{~ms}$, $P$-wave dispersion was significantly greater than in those with $Q T$ dispersion values $<100 \mathrm{~ms}(58 \pm 16 \mathrm{vs} 53 \pm 12 \mathrm{~ms}, \mathrm{p}=0.04)$.

Conclusion - Our results suggest that, in elderly patients with heart failure, a correlation between the values of $P$-wave and $Q T$ dispersions exists. These findings may have etiopathogenic, pathophysiologic, prognostic, and therapeutic implications, which should be investigated in other studies.

Keywords: P-wave dispersion, QT dispersion, heart failure

Instituto do Coração do Hospital das Clínicas da FMUSP

Mailing address: Claudia Szlejf - InCor - Departamento de Cardiogeriatria - Av. Dr. Enéas C. Aguiar, 44 - 05403-000 - São Paulo, SP, Brazil - E-mail: mauriciowa@hotmail.com.br

English version by Stela Maris C. e Gandour
Dispersion of the QT interval (QTd) is defined as the difference between the longest and the shortest QT interval in all electrocardiographic leads, which may be possibly measured. That parameter electrocardiographically translates the asynchrony of repolarization of ventricular myocardial rows, which is a phenomenon predisposing patients to an abnormal flow of the electric current in the heart. The increase in QT dispersion seems to have a prognostic meaning for several groups of patients and is associated with nonhomogeneous ventricular repolarization, which may favor reentry mechanisms, and, consequently, the appearance of ventricular arrhythmias ${ }^{1,2}$. Batchvarov and Malik ${ }^{3}$ have reported that QTd should be greater than $100 \mathrm{~ms}$ to be interpreted as a signal of abnormality in the course of ventricular repolarization. Some studies have shown that individuals with heart failure have greater QTds, suggesting that this electrocardiographic parameter can serve as a predictor of ventricular arrhythmias ${ }^{4-6}$.

The concept of $\mathrm{P}$-wave dispersion $(\mathrm{Pd})$ has been recently established as the difference between the longest and the shortest $\mathrm{P}$-wave duration in all electrocardiographic leads. An increase in Pd indicates heterogeneous atrial repolarization, favoring reentry mechanisms. Similar to that which happens with the increase in QTd, the increase in Pd can be a predictor of supraventricular arrhythmias ${ }^{7-9}$. Several studies have suggested that the greatest $\mathrm{P}$-wave dispersion measured in a 12-lead electrocardiogram is an independent predictor of paroxysmal atrial fibrillation ${ }^{7,8,10}$. Other authors have confirmed this hypothesis with signal-averaged electrocardiography ${ }^{11-13}$. So far, no study using body surface mapping has been carried out. Body surface mapping is a noninvasive method that can show the spatial distribution of body surface potentials, providing tridimensional details on the electrocardiogram ${ }^{14,15}$ similar to those obtained with an invasive method ${ }^{16}$. Its 87 leads distributed all over the thorax provide more prognostic and diagnostic information than the conventional electrocardiogram (with 12 
leads distributed only on the precordium) ${ }^{17}$. Therefore, it is a more appropriate method for studying Pd.

Patients with heart failure have alterations in the conduction of the stimulus in the atria and ventricles, possibly due to an increase in Pd and QTd.

\section{Methods}

We studied consecutively 47 elderly patients (age $>65$ years) with heart failure, who were registered at the Heart Failure Outpatient Clinic of the Cardiac Geriatric Clinical Unit of the Instituto do Coração of the Hospital das Clínicas of the Medical School of the University of São Paulo. All patients had stable heart failure and were in NYHA functional classes II or III. Their ejection fraction obtained on the echocardiogram was lower than $50 \%$ (tab. I). All patients had undergone extensive clinical and laboratory investigation to eliminate any possible doubt about the diagnosis. Patients who did not have sinus rhythm at the time of the evaluation were excluded from the study. The Committee on Ethics of the hospital approved the study protocol, and all patients signed a written consent form before the beginning of the study.

The Mapping System HPM - 7100 from Fukuda Denshi with 87 leads was used for body surface mapping. The patients were put in the dorsal decubitus position with 59 leads on the anterior part of the thorax and 28 leads on the dorsum. The measurements were taken in a semi-automatic manner with 2 mobile pointers moved manually on the monitor of the device by 1 single observer. The P-wave dispersion was calculated based on the difference between the maximum and minimum values of the interval between the beginning of the $\mathrm{P}$ wave and the beginning of the QRS complex on the 87 leads. The difference between the maximum and minimum values of the interval between the beginning of the $Q$ wave and the end of the $T$ wave in all leads was considered the QT dispersion.

The Pearson correlation test was used to compare QT and P-wave dispersions. In addition, the patients were separated into 2 subgroups according to QTd with $100 \mathrm{~ms}$ used as the cut-off value, as suggested by Batchvarov and Malik $^{3}$. The Student $t$ test was used to compare Pd values between the subgroups. P values $<0.05$ were considered statistically significant.

\section{Results}

Dispersion of the QT interval was $68.2 \pm 27.1 \mathrm{~ms}$, ranging from 28 to $141 \mathrm{~ms}$. Dispersion of the $\mathrm{P}$ wave was $54.7 \pm 14.5 \mathrm{~ms}$, ranging from 20 to $94 \mathrm{~ms}$.

A significant correlation between QTd and Pd was observed $(\mathrm{R}=0.41$ and $\mathrm{p}=0.04)$ (fig. 1 ).

The patients with QTd $>100 \mathrm{~ms}$ had a significantly greater Pd than those with QTd $<100 \mathrm{~ms}$ (tab. II).

\section{Discussion}

In the elderly patients with stable heart failure, a significant and positive correlation between Pd and QTd values

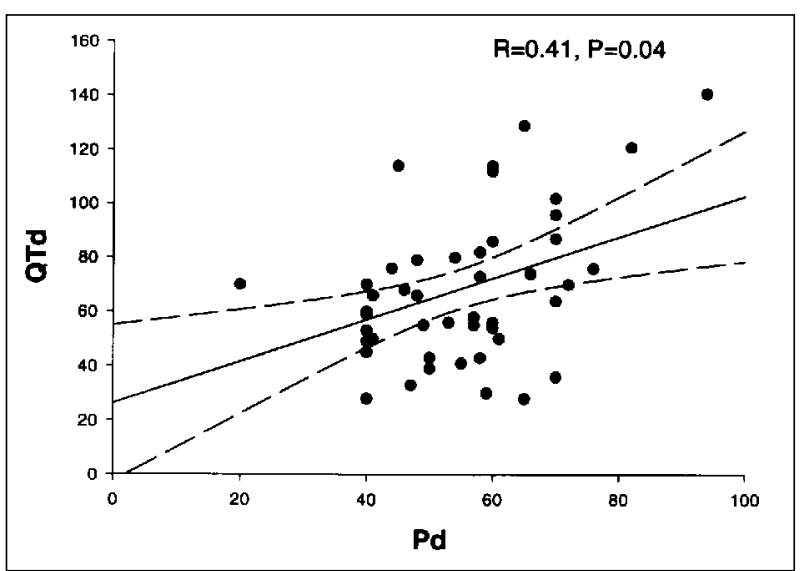

Fig. 1 - Relation between Pd and QTd. The relation between Pd and QTd is positive and significant $(\mathrm{R}=0.41$ and $\mathrm{p}=0.04)$.

was observed. Patients with QTd $>100 \mathrm{~ms}$ showed a significantly greater Pd than those with QTd lower than that value.

As far as we know, this is the first study assessing the relation between Pd and QTd. This relation probably indicates the existence of a mechanism of heterogeneous atrial and ventricular repolarization with a common substrate in patients with heart failure.

The physiopathogeny of the alterations of repolarization, which lead to arrhythmias, may be considered multifactorial with the following determinant factors: a) cardiac chamber size, b) myocardial fibrosis, and c) tonus of the autonomic nervous system.

Dilation and hypertrophy of the cardiac chambers due to myocardial overload in heart failure may lead to an alteration in the architecture of the cardiac fibers, interfering with the conduction of the electric impulses. However, Zaman etal ${ }^{18} \mathrm{did}$ not find any relation between left atrial size and the duration of the $\mathrm{P}$ wave on signal-averaged electrocardiography of patients undergoing myocardial revascularization. A previous and still unpublished study carried out at our institution showed no relation between left atrial size and Pd in elderly patients with heart failure.

Myocardial fibrosis, on the other hand, may cause electrical heterogeneity and anisotropic arrhythmias due to reentry ${ }^{19}$. The presence of ischemia or the activation of the renin-angiotensin-aldosterone system found in coronary

\begin{tabular}{|lll|}
\hline & Table I - Case series \\
\hline Age (years) & $75.5 \pm 6.21$ & $(65-89)$ \\
Males/females (n) & $26 / 21$ \\
Ejection fraction $(\%)$ & $37.3 \pm 6.3$ & $(15-50)$ \\
\hline
\end{tabular}

\begin{tabular}{|lllc|}
\hline \multicolumn{4}{|c|}{ Table II - Pd and QTd greater and smaller than $\mathbf{1 0 0}$ ms } \\
\hline \\
\hline QTd $>100 \mathrm{~ms}$ & $\mathrm{QTd}<100 \mathrm{~ms}$ & $\mathrm{p}$ \\
\hline $\mathrm{Pd}(\mathrm{ms})$ & $68 \pm 16$ & $53.2 \pm 12.1$ & $<0.05$ \\
\hline
\end{tabular}


artery disease could account for the remodeling of the cardiac fibers ${ }^{20}$. The investigation of the fibrous cardiac area is known to depend on sophisticated imaging methods, such as magnetic nuclear resonance. Studies with specialized techniques should be conducted to relate QTd and Pd to the extension of the fibrosis.

It has been reported in the literature that an increase in the sympathetic tonus in heart failure may justify the presence of the prolonged QTd in these patients ${ }^{4,6}$. Even though differences in the atrial and ventricular autonomic tonus may be found, the sympathetic activation of both cardiac chambers due to heart failure may justify the correlation between Pd and QTd.

It is worth repeating that the population studied consisted of elderly patients with NYHA functional classes II or III for heart failure. These patients were in an advanced stage of the disease with probable impairment of the 4 cardiac chambers. Therefore, a correlation between the dispersion of atrial repolarization, represented by Pd, and the dispersion of ventricular repolarization, represented by QTd, may exist. These findings cannot be extended to patients in an earlier phase of heart failure.

QTd and Pd may perhaps be considered electrocardiographic markers predictive of arrhythmias in patients with heart failure. However, studies with long-term follow-up should be conducted to confirm this possibility, so that these parameters can be used in clinical practice.

In conclusion, our results suggest that a relation between P-wave and QT dispersion values exists in elderly patients with heart failure. These findings may have etiopathogenic, physiopathologic, prognostic, and therapeutic implications for the appearance of arrhythmias in these patients.

\section{References}

1. Lombardi F. The QT interval and QT dispersion: the smaller, the better! Eur Heart J 1998; 19: 1279-81.

2. Zabel M, Portnoy J, Franz M. Electrocardiographic indexes of dispersion of ventricular repolarization: na isolated heart validation study. J Am Coll Cardiol 1995; 25: 746-52.

3. Batchvarov V, Malik M. Measurements and interpretation of QT dispersion. Progress Cardiovasc Dis 2000; 42: 325-44.

4. Bonnar CE, Davie AP, Caruana L, et al. QT dispersion in patients with chronic heart failure: $b$ blockers are associated with a reduction in QT dispersion. Heart 1999; 81: 297-302.

5. Galinier M, Vialette J-C, Fourcade P, et al. QT interval dispersion as a predictor of arrhythmic events in congestive heart failure. Importance of aetiology. Eur Heart J 1998; 19: 1054-62.

6. Peris VB, Menadas JVM, OrtuñoFM, et al. Dispersión del intervalo QT em pacientes ingresados por insuficiencia cardíaca. Determinantes y valor prognóstico. Rev Esp Cardiol 1999; 52: 563-9.

7. Ciaroni S, Laurence C, Bloch A. Clinical study to investigate the predictive parameters for the onset of atrial fibrillation in patients with essential hypertension. Am Heart J 2000; 139: 814-19.

8. Dilaveris PE, Gialafos EJ, Andrikopoulos GK, et al. Clinical and electrocardiographic predictors of recurrent atrial fibrillation. PACE 2000; 23: 352-8.

9. Tükek T, Akkaya V, Demirel S, etal. Effect of Valsalva Maneuver on surface electrocardiographic $\mathrm{P}$-wave dispersion in paroxysmal atrial fibrillation. Am J Cardiol 2000; 85: 896-8.

10. Dilaveris PE, Gialafos EJ, Sideris SK, et al. Simple electrocardographic markers for the prediction of paroxysmal idiopathic atrial fibrillation. Am Heart J 1998; 135: 733-8.

11. Kubara I, Ikeda H, Hiraki T, Yoshida T, Ohga M, Imaizumi T. Dispersion of filtered
P wave duration by $P$ wave Signal-averaged ECG Mapping System: Its usefulness for determining efficacy of disopyramide on paroxysmal atrial fibrillation. J Cardiovasc Electrophysiol 1999; 10: 670-9.

12. Villani GQ, Massimo P, Rosi A, Capucci A.P-wave Dispersion Index: a marker of patients with paroxysmal atrial fibrillation. Int J Cardiol 1996; 55: 169-75.

13. Yamada T, Fukunami M, Shimonagata $T$, et al. Dispersion of signal-averaged $P$ wave duration on precordial body surface in patients with paroxysmal atrial fibrillation. Eur Heart J 1999; 20: 211-20.

14. Miller JM, Zipes DP. Management of the patient with cardiac arrhythmias. In: Braunwald E, ed. Heart Disease: A Textbook of Cardiovascular Medicine, $6^{\text {th }}$ ed. St. Louis: WB Saunders Co., 2001: 700-74.

15. Mirvis DM, Golberger AL. Electrocardiography. In: Braunwald E, ed. Heart Disease: A Textbook of Cardiovascular Medicine, $6^{\text {th }}$ ed. St. Louis: WB Saunders Co., 2001: 82-128.

16. Lux RL, Fuller MS, MacLeod RS, Ershler PR, Punske BB, Taccardi B. Noninvasive indices of repolarization and its dispersion. J Electrocardiol 1999; 32(suppl): 153-7.

17. Taccardi B, Punske BB, Lux RL, et al. Useful lessons from body surface mapping. J Cardiovasc Electrophysiol 1998; 9: 773-86.

18. Zaman, AG, Archbold A, Helft G, Paul EA, Curzen NP, Mills PG. Atrial fibrillation after coronary artery bypass surgery: a model for preoperative risk stratification. Circulation 2000; 149: 251-66.

19. Schneider CA, Voth E, Baer FM, Horst M, Wagner R, Sechtem U. QT dispersion is determined by the extent of viable myocardium in patients with chronic Q-wave myocardial infarction. Circulation 1997; 96: 3913-20.

20. Darbar D, Luck J, Davidson N, et al. Sensitivity and specificity of QTe dispersion for identification of risk of cardiac death in patients with peripheral vascular disease. Br Med J 1996; 312: 874-8. 